\title{
The Dynamic Structure Of Customer Relationship Management With Implications For Business Implementation
}

\author{
Kuan C. Chen, Purdue University Calumet
}

\begin{abstract}
CRM (Customer Relationship Management) is a systematic business approach using information and on-going dialogue to build long lasting and mutually beneficial customer relationships. CRM integrates data, technology, analyses and marketing and communications processes across all customer touch-points. CRM can be an effective business strategy tool when used appropriately, especially now in our customer center business. To the end, a holistic view of the implementation of CRM should be made in order to discuss the pro and con about this strategy. This paper will review a number of CRM literatures and a conceptual systems thinking model will be built to explore these Customer Relationship Management related components to guide the administrators as they attempt to steer the Customer Relationship Management clear of these obstacles. Specifically, systems feedback loops as a tool to demonstrate the dynamic structure of Customer Relationship Management components and assist the management control policy scenario planning.
\end{abstract}

Keywords: Customer Relationship Management, systems thinking, scenario planning

\section{INTRODUCTION}

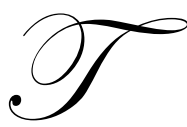

oday's business world is one of intense competition from all sides. In order to combat this unrelenting burden, companies must look at every aspect of their business to create a sustainable competitive advantage to secure a future in the marketplace. Almost every industry is being challenged to find creative new ways to reducing costs while improving product offerings. A major trend in this are is a concept known as Customer Relationship Management (CRM). CRM gives a company the ability to offer more than just a product, but build a relationship with customers that is mutually rewarding and successful.

CRM is a concept that has been around for a long time but until recently, it was usually passed off as simply sales people trying to build a personal relationship with customers. With today's almost unlimited uses of computers, it includes much more. Benefits range from using customer feedback to develop new products to saving cost for sales managers. The ultimate goal of a CRM system is to increase profile and help build a future place for the business.

CRM can be defined as a system that compiles large amounts of customer data and presents it in a usuable manner. This information can help almost every facet of a business and can be presented in an individualized manner. This enables easier and more accurate decision making. By offering real time data and using push reporting to show trends, CRM can greatly improve the efficiency and effectiveness of most business departments. These departments include sales, marketing, product development, and resource planning, all of which are essential for a company's prosperous future. 


\section{MARKETING}

The importance of marketing to a competitive business strategy becomes apparent when investigating the four key areas of the field: product, price, place, and promotion. All areas must be examined closely if an effective strategy is to be implemented. Product is concerned with what a company is offering. It is important to know what the consumer wants and to tailor the product to meet these wants. This can only be done properly with accurate customer feedback. Price is very influential to many customers' perceptions in different products. W8ith proper marketing research, it is possible to determine the maximum selling price while still keeping customer interest. Consumers can be turned off to prices that are too high as well as prices that are to low. Place becomes important when considering in what markets products should be offered. Certain products will have markets in which they are better received due to a wide variety of reasons such as geography or demographics. It is important that these issues are well known before markets are targeted. Finally, promotion is the fourth key area when determining a marketing strategy.

Customers will react differently to know they are approached. Using the proper combination of advertising, sales promotion, personal selling, and public relations will help companies capitalize on every dollar spent. IT is very important all these areas are focused on the overall computer strategy. Synchronizing a company's marketing efforts with the overall company strategy can be extremely time consuming. The compilation and data analysis required can be more easily accomplished with the implementation of a proper CRM system. CRM systems can even incorporate push reporting which will inform the usher the best theoretical approach.

\section{PRODUCT DEVELOPMENT}

Product development and improvement is essential to any business to establish a sustainable competitive and advantage. Company strategy should envelope and be steered with consideration to this functional group. Today's world requires products and services to continually improve. Whether it is for a new product introduction, a needed additional feature on an existing product or the correction of a problem on an existing product, if the improvements do not occur, some other enterprise will rise to the challenge and consume the market. Change is not the only variable though; it must come with proper timing, both quickly and precisely. The success of new product introductions can be greatly impacted by when it is first offered relative to the market conditions. Many companies have found difficulty in starting a marketing campaign at the wrong time.

CRM and the product development group are related through the generation of ideas for improvement $\mathrm{s}$ and new products. CRM, through customer feedback data, can show where deficiencies exist and lead analysts to better conclusions regarding these deficiencies by recognizing trends and acting on them.

\section{RESOURCE PLANNING}

For any company, scheduling resources is a key factor in success. An enterprise must have sufficient equipment, raw materials, plants, or people to satisfy its market share requirements. However, having too much of any one of these resources is costly. Precisely knowing needed resource in advance gives a firm an advantage in that only the necessary amount of each could be purchased and delivered at the correct time. This reduces carrying costs and other expenses associated with excess. The difficulty lies in predicting spikes and lulls in activity. If it were possible to predict the ups and downs, planning for them would be possible and a more consistent allocation would result.

CRM makes this consistency possible by analyzing past trends and using them to predict future requirements. This is especially helpful in anticipating seasonal needs and product life cycle stages. The end result is more stability, better allocation of resources, and lower operating costs. 


\section{INFORMATION TECHNOLOGY}

A strong and capable information technology group is essential for reaping the benefits of a good CRM system. The IT group will be responsible for maintaining and managing the integrity of a CRM database. Sufficient budges must exist in order to accomplish this effectively. Whether it be for hiring highly skilled people or purchasing better equipment and software, management must be willing to invest in a sound IT department. This investment must make sense from a return point of view, but all of the benefits must be weighed including intangible ones.

The link between CRM and IT helps to unite the IT department with the rest of the company in that it ties IT into the business strategy. CRM, if used properly, should be an active and important component of any enterprise's business strategy. CRM has the potential to add value to the firm and to a product offering for a customer. However this is limited by the resources and abilities of the IT department.

\section{CUSTOMER SERVICE}

The importance of customer service can easily be forgotten after a sale. Out of sight, out of mind can be detrimental company philosophy. Customer service consists of many factors such as complaint management, problem recognition, service staff scheduling, and appropriate responses. No matter how well a product is made, complaints are still going to come. Properly managing complaints requires attention and a good tracking system. If complaints come in and sit on a desk for an extended period of time, customer satisfaction will be negatively affected. Problem recognition is also very important in the area of customer service.

Proper customer attention can help identify problem areas sometimes before the customer even knows. This can even result in preemptive corrective actions. Automakers have been doing this for many years and sending out recall notices. Customers are disappointed that there is a problem with the product they bought, but overall pleased with the fact that steps are being taken to correct it. With more products being sold, the number of service people will normally increase which will amplify the importance of service staff scheduling. When customers have problems, it is often important to have a service person present. Getting these people to the right places at the right time can require serious attention. Finally, appropriate responses can be extremely different from one customer to the next. Knowing if a customer prefers a personal visit or simply a phone call requires knowledge of that customer. All of these customer service issues require large amounts of attention that is often not properly given to them.

\section{SALES}

The sales efforts of a company are crucial as well as costly. It is important that the right efforts are being made and as little time is wasted as possible. Much like marketing it is important to know about the customer. The sales staff will be much more efficient given as many details about a customer as possible. It is also extremely costly to support a strong sales force. For this reason it is very desirable to focus sales efforts to those accounts mostly likely to result in a sale and thereby reducing the amount of wasted time and effort. Comparing the prospects of different accounts is very difficult and can be very subjective. These are all tasks that the sales management must undertake. IT is very important that all be done in a timely and unbiased fashion. This can be very difficult without the help of CRM system.

To ultimately relate a CRM system to profitability, the following thought loops are depicted and described. These loops show several examples of CRM indirectly, positively impacting overall profitability.

\section{RESOURCE PLANNING LOOP}

Resource planning is a means for predicting future needs of capital, raw materials, equipment, labor, etc. in an effort to control fluctuations and maximize the effectiveness of all a company's assets. CRM allows for increased accuracy in this planning by identifying trends in customer purchasing habits, and offers a more effective use of customer feedback. This feedback would include such things as sales projections, inventory levels and 
inventory control. Resource planning through CRM can easily be depicted with the following balancing loop scenario.

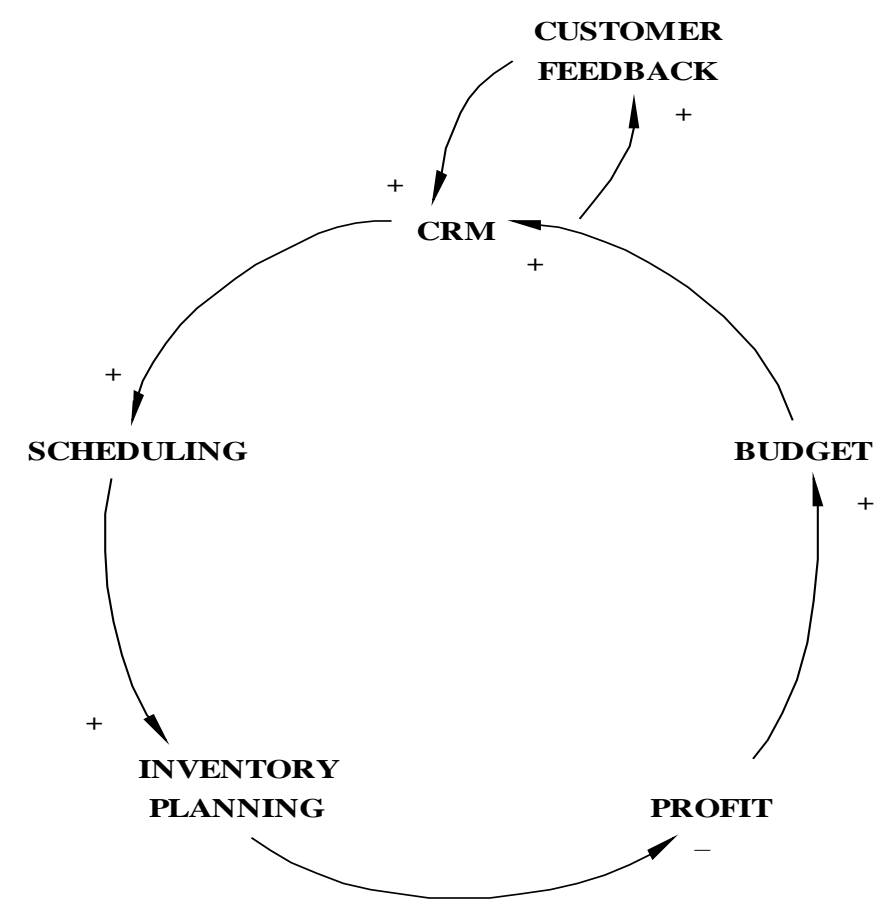

Figure 1: Resource Planning Loop

As a company's CRM applications resources are improved, the organization of customer feedback data and trend recognition become more precise and useful. This enables a planner to more quickly and accurately interpret future production requirements by organizing and presenting data in the form that is more applicable. CRM allows for direct feedback with regard to seasonal changes in publishing habits, phasing out of product lines, and fluctuations in demand due to market share changes. Truthful production scheduling is the essential first step in internal inventory control. By precisely pinpointing production schedules, inventory fluctuations can also be predicted and inventory levels can be controlled and minimized. Inventory reductions allow for decreasing inventory carrying costs and free up cash that could be allocated to other profit making ventures. Another use of this cash and profit from reduced costs would be to improve the company's CRM application resources and thus closing the loop.

\section{PRODUCT DEVELOPMENT LOOP}

Product development is essential to any company's sustainable strategic position. Typically, product development comprises long term thinking with the intent of future prosperity. It can consist of revisions to current products or introductions of new products to the marketplace. Product development requires many resources to join together for a common goal.

The first step in development is idea generation. Ideas can come from many sources but ultimately need to be structured around the customer feedback. "Limiting the search for new product ideas to those generated by 
internal research and development activities is far too narrow an approach for most firms." ${ }^{\text {1 }}$ By simply relying on internal resources, product development will often fall short on desired results. Customer feedback gives insight on true application situations and offers a panoramic view of beneficial features.

The next step in this process is to test the idea's feasibility. Typically this would involve taking prototype products to the customer for scrutinization and feedback. By relying on customer opinion in this sage, potentially large amounts of money could be saved by not pursuing products that no one will purchase.

If the idea is deemed to be feasible, the last stages in development involve finalizing the design and marketing mix based on previously discussed feedback from customers. Insights gained from the marketing research done during the feasibility testing stage help to define things such as pricing, promotion and introduction strategies. This will ultimately lead to increased market penetration when the product is released and should reduce the potential for failure of a product.

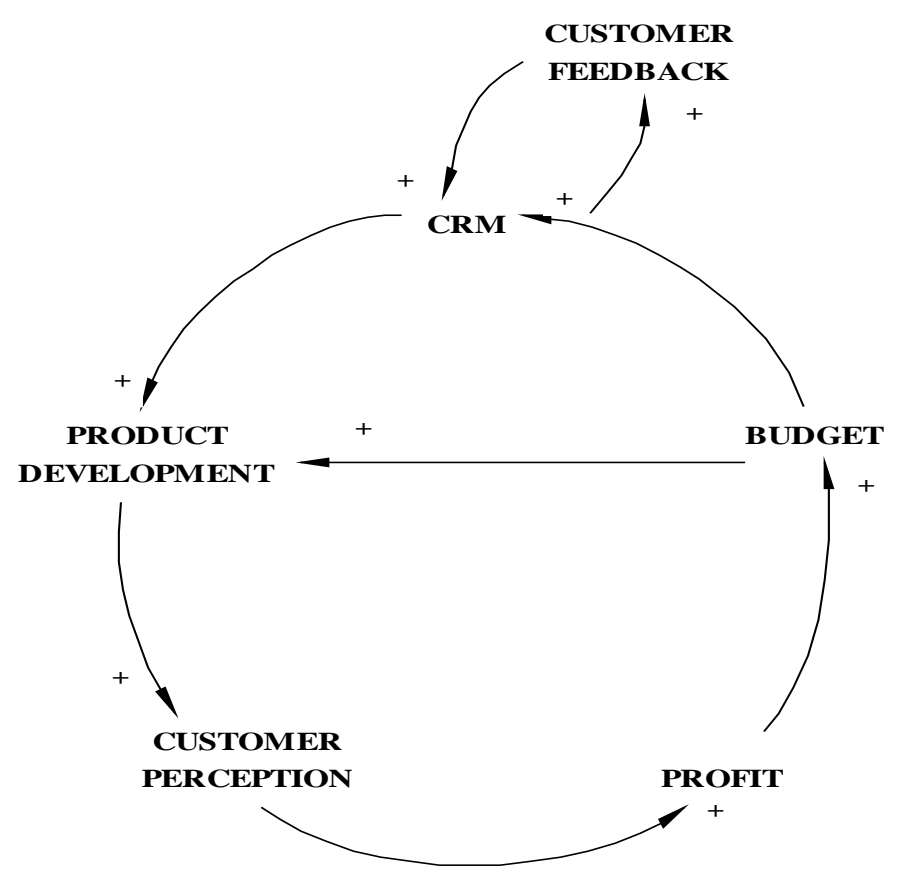

Figure 2: Product Development Loop

The above loop shows how CRM ultimately leads to successful new product development and improvements to add to overall profitability. It begins with CRM taking marketing information, including customer feedback, and organizing and presenting data to the product development group in terms of desired attributes. These attributes are then converted into product features that conform to marketing strategies and customer value perception. If the marketing data obtained was accurate and the product development group implemented it properly high customer satisfaction should be achieved. High customer satisfaction will lead to repeat buyers and increased market share, ultimately, higher profitability will be realized. This higher profitability will increase the amount of fund to be budgeted. These budgeted funds can then close the loop by increasing funds spent on CRM. Other areas in which this budgeted money will go to are marketing and product development.

\footnotetext{
${ }^{1}$ Strategic Marketing, Seventh edition. Written by David W. Cravens, and Nigel F. Piercy. Published by McGraw-Hill 2000. Page 263.
} 


\section{CRM IMPLEMENTATION LOOP}

Many organizations, while attempting to implement CRM systems, run into obstacles that can hinder the success of the program. These problems generally stem from reluctance on the part of employees and a negative attitude toward change. They are easily avoided by proper planning and training. Employees are more eager to accept change when a clear path has been defined and expected results show substantial rewards for changing comfortable methods. The most difficult part of implementing a CRM system is for management to develop a situation through creating clear valid and attainable goals and compelling employees to reach those goals. By properly setting and communicating goals, management creates a situation were employees, in an effort to avoid cognitive dissonance, will work hard and use the system to its fullest potential. Many examples exist in today's business world that shows failures in the implementation of CRM programs. Reports range from 25-65\% of all attempts at these kinds if systems end in failure. ${ }^{2}$

The common thread in all of these failures is employee conformance. Ojas Rege states "low sales representative compliance compromises data quality; and a CRM system with incomplete data is of minimal use."3 If everyone is not on board and does not see how the system adds value to the firm and ultimately to the product offering, the usefulness of the entire system will be drastically diminished. Inaccurate and incomplete data compromises the integrity of the system. If bad data is entered, the inevitable outputs are a misrepresentation of actual facts. When these erroneous outputs are scrutinized and revealed as incorrect, faith in the system is lost. Without this faith employees will be less willing to take the time to enter the necessary data.

The unwillingness to allocate time to data entry may also be a result of the inability to associate any direct relationship between the input and useful outputs. Each employee must see benefits to the system that encourage participation. An example of this would be sales or service people in the field will be unwilling to spend time entering data if it does not result in meaningful conclusions that help them make more efficient use of time and other resources. When properly implemented CRM systems can actually help sales representatives spend more time with customers getting orders and less time chasing information.

Ultimately, the goal is to get sales orders to increase profitability. Therefore, any CRM system that is to be accepted must also be able to help profitability. By training employees in the rewards available from using the system and in the system itself, acceptance will be greater and the quality of the information will be enhanced. If the system is accepted and management is committed to adequate training, the profitability of success will be greatly increased. However, the system must be user friendly and arranged logically and concisely. Because these systems are often expensive, every effort must be made to ensure success.

\footnotetext{
${ }^{2}$ Jeff Sweat, When CRM failure Isn't, CRMGuru, May 16, 2002, Available at www.crmguru.com.

${ }^{3}$ Ojas Rege, Stripping Down CRM to Pint-Size Simplicity, CRMGuru, March 18, 2003, Available at www.crmguru.com.
} 


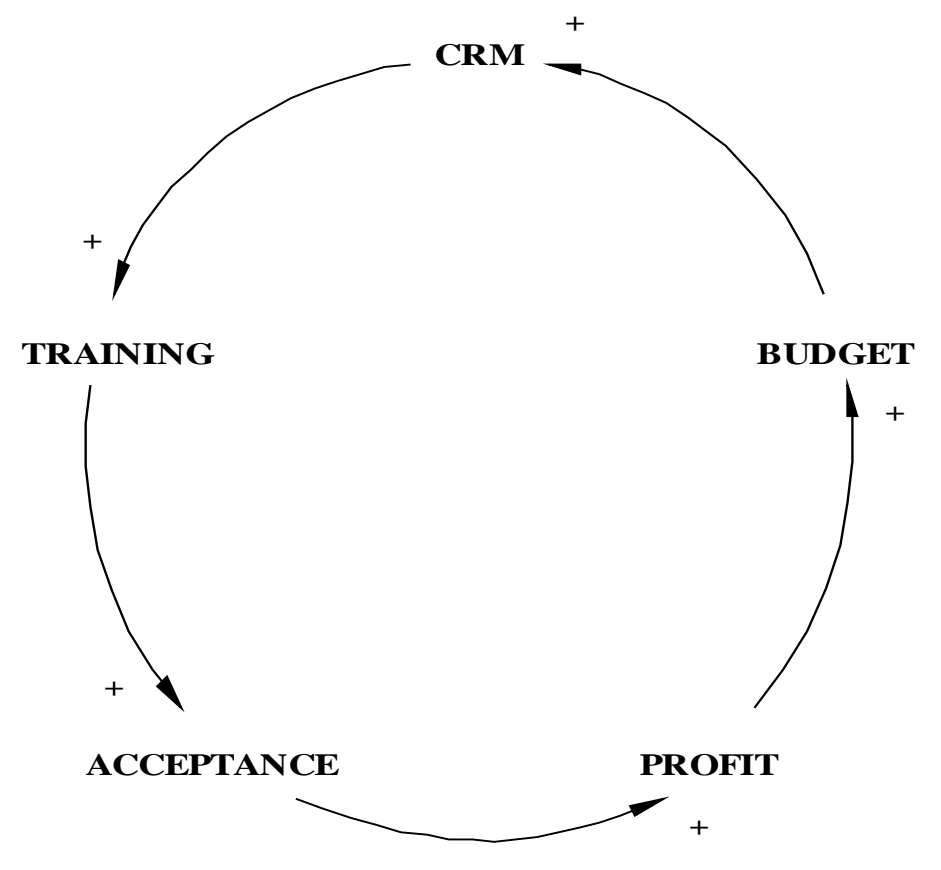

Figure 3: CRM Implementation Loop

Success in the program will lead to profitability through a more efficient and effective sales staff and more accurate and timely information for making better decisions. For example, one customer says, "the number of contacts turned into effective sales increased dramatically, resulting in $\$ 50$ million more sales in the call center channel alone." 4 A CRM system helps sales representatives more efficiently target revenue generating prospects by proportioning the amount of time spent with the amount of sales generated during routine visits. A customer that historically does not generate a lot of revenue should not get as much attention as a customer who generates large percentages of total income.

By enhancing total income, it can be deduced that total profitability will also increase. This increase leads to more potential for an enterprise to budget money for improvements to any of the necessary functional areas including CRM for system upgrades and training of employees. This increase in budgeting potential essentially closes the loop for successful implementation.

\section{CUSTOMER SATISFACTION LOOP}

Customers' dissatisfaction with some or all aspects of a product offering is an inevitable part of conducting business. However, sometimes the potential for repeat sales is contingent upon reaching an amicable conclusion to the situation. CRM aides in this process by quickly routing customer problem information to people who are able to handle the situation in a timely and accurate manner. This also allows for an enterprise to be proactive in solving customer problems. If a particular product has difficulty at one customer and is used by others, a similar situation can be avoided before it arises by having a plan in place to correct the problem. If a customer is consuming excessive inventory, a service representative could be notified and the cause for the higher than normal usage could be explored.

\footnotetext{
${ }^{4}$ Richard Forsyth, Next Best Activity - Jewel in the CRM Implementation Crown, CRM-Forum, September 1, 2002, Available at www.crm-forum.com
} 
By being proactive when possible and reacting promptly to problems, an enterprise can improve customer satisfaction ratings. Customer satisfaction can also be enhanced by increasing the availability of specific information. For example, a CRM program could allow limited access to data showing status of an order via the Internet. If a customer sees value in this type of access, he will be more satisfied with the product offering. By allowing for free access between the enterprise and its customers, and relationship can be developed based on trust. These relationships result in more loyal purchasing habits and ultimately a more profitability. This type of relationship building has been beneficial for one company; "eventual customer defection rate of around $2 \%$ and a referral rate of over $80 \%, " 5$

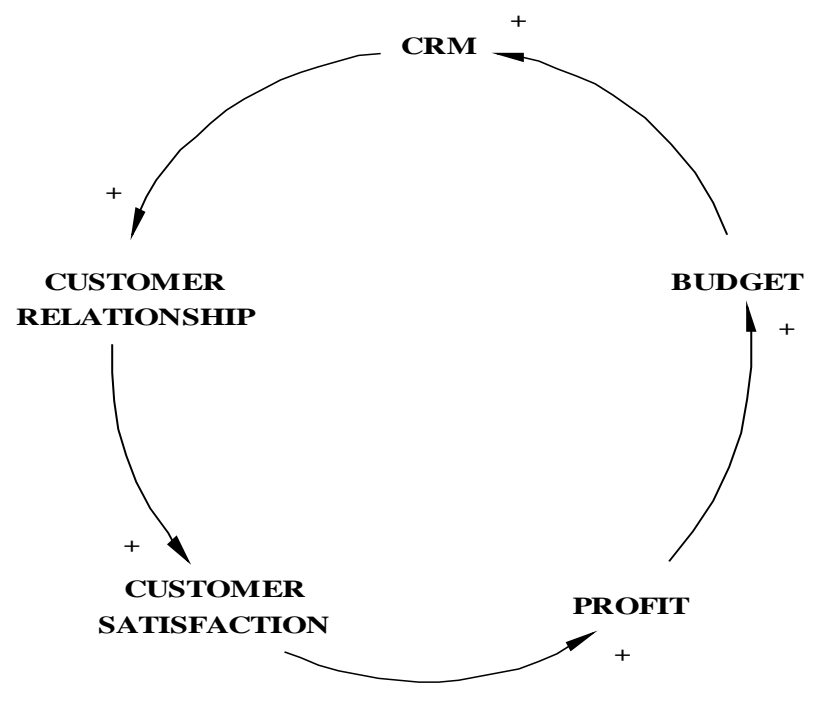

Figure 4: Customer Satisfaction Loop

Strong relationships ultimately lead to better communication and satisfaction. This satisfaction leads to increased sales revenue. Increased profitability will be the outcome of the increased revenue. This profitability will allow for more budgetable resources. These resources can be allocated to the CRM program.

\section{IT LOOP}

Labor costs are a large part of any organizational outlook. With today's high wages, increasing health insurance costs, and benefit demands, any reduction in labor force could have great impact on overall profitability. A well developed CRM program products outputs and recommendations at much greater speeds and with more accuracy than even large groups of analysts would. Sales representative time could be used much more efficiently and effectively by inducing a focus on high revenue customers. This time would also have a more definite purpose there fore less would need to be spent repeating similar actions. With almost immediate access to information, less time is spent digging and sorting. As mentioned above with the CRM information on a computer system, production and inventory planning is improved. Part of this improvement is the lesser need for expeditors and manual scheduling.

\footnotetext{
${ }^{5}$ Richard Forsyth, Next Best Activity - Jewel in the CRM Implementation Crown, CRM-Forum, September 1, 2002, Available at www.crm-forum.com
} 


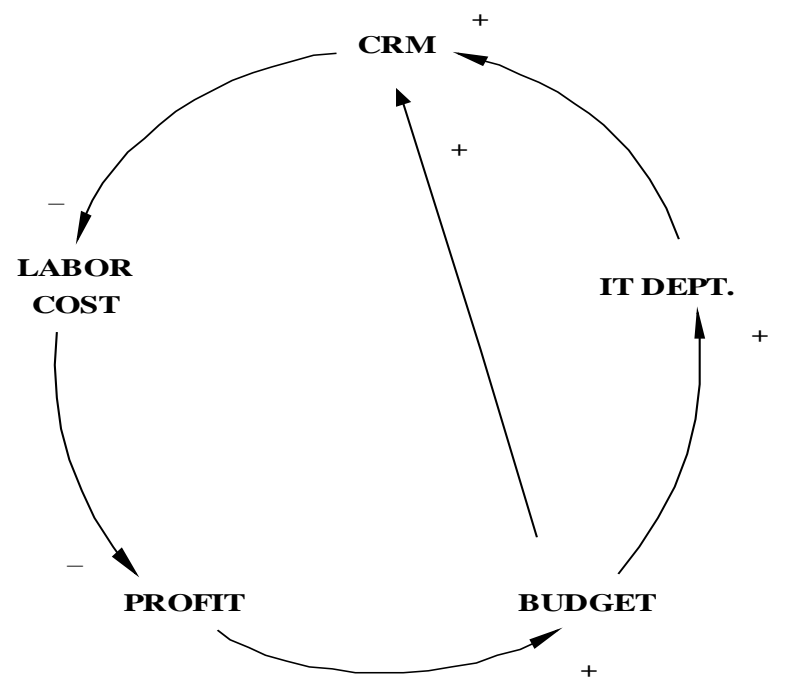

Figure 5: IT Loop

As the above loop shows, the IT department is the backbone of an efficient CRM program. As the IT department improves, so does the CRM application potential. As the CRM system improves, there will be a decreasing need for man power. This reduction in the labor requirement reduces overall operating costs. The need for highly paid staff employees will also be curtailed to a more favorable level. The down scaling allowed by the CRM implementation, in turn increase potential profitability. Profitability will add to the dollar amount to be budgeted to the company in the following year. Seeing the positive results of the IT department and the CRM system, it is likely more money will be allocated to these areas.

\section{CONCLUSION}

CRM is a system to enhance and support the efforts of the company as a whole by organizing and analyzing customer information to help guide. If implemented correctly, CRM can be a great tool for improving profitability, customer satisfaction, and reducing overall costs. Cost reduction can be realized in many functional aspects of an enterprise most notable, by making efforts make efficient and effective $\mathrm{n}$ the areas of sales, resources planning and product development. Though CRM has its share of critics, it is generally the implementation that is at fault and not the system itself. As with most situations that involve change prior proper planning prevents piss-poor performance.

\section{REFERENCE}

1. Adam., Mulye, R., \& Deans, K. R. (2001). Chapter 14: The evolution of relationships in e-marketing. In J. N. Sheth, A. Parvatiyar \& G. Shainesh (Eds.), Customer relationship management: Emerging concepts, tools and applications (pp. 135-142). New Delhi, India: Tata McGraw Hill.

2. Anton, J., \& Vilsoet, B. (2002). Customer relationship management technology: Infrastructure for customer collaboration. Santa Maria, CA: BenchmarkPortal, Inc.

3. Arndt, D., \& Gersten, W. (2001). Data management in analytical customer relationship management. Retrieved November 9, 2002, from http://www.luc.ac.be/iteo/articles/arndt_gersten.pdf

4. Barnes, J. G. (2002). Secrets of customer relationship management: It's all about how you make them feel. Journal of Services Marketing, 16(7), 700-703.

5. Bergeron, B. P. (2002). Essentials of CRM: A guide to customer relationship management. New York, NY: John Wiley \& Sons, Inc. 
6. Berry, M. A., \& Linoff, G. S. (2000). Mastering data mining: The art and science of customer relationship management. Industrial Management \& Data Systems, 100(5), 245-246.

7. Bose, R. (2002). Customer relationship management: Key components for IT success. Industrial Management \& Data Systems, 102(2), 89-97.

8. Brown, S. A., \& Price Waterhouse Coopers. (1999). Customer relationship management: A strategic imperative in the world of e-business. New York, NY: Wiley, John \& Sons, Inc.

9. Campbell, A. J. (2003). Creating customer knowledge competence: Managing customer relationship management programs strategically. Industrial Marketing Management, 32(5), 375-383.

10. Chen, I. J., \& Popovich, K. (2003). Understanding customer relationship management (CRM): People, process and technology. Business Process Management Journal, 9(5), 672-688.

11. Chen, R.-S., Chen, M.-H., Chang, C. C., \& Hsu, S.-H. (2002). Design and implement a web-based customer relationship management prototyping system. International Journal of Computer Applications in Technology, 15(6), 297-305.

12. Corner, I., \& Hinton, M. (2002). Customer relationship management systems: Implementation risks and relationship dynamics. Qualitative Market Research: An International Journal, 5(4), 239-251.

13. Cravens, D. W. \& Piercy, N. F. (2000). Strategic Marketing, $7^{\text {th }}$ Ed. Boston, McGraw-Hill.

14. Crosby, L. A. (2002). Exploding some myths about customer relationship management. Managing Service Quality, 12(5), 271-277.

15. Dibb, S. (2001). Banks, customer relationship management and barriers to the segment of one. Journal of Financial Services Marketing, 6(1), 10-23.

16. Dibb, S. (2001). Banks, customer relationship management and barriers to the segment of one. Journal of Financial Services Marketing, 6(1), 10-23.

17. Fayerman, M. (2002). Customer relationship management. New Directions for Institutional Research, 2002(113), 57-68.

18. Feinberg, R. A., Kadam, R., Hokama, L., \& Kim, I. (2002). The state of electronic customer relationship management in retailing. International Journal of Retail \& Distribution Management, 30(10), 470-481.

19. Forsyth, R., Next Best Activity - Jewel in the CRM Implementation Crown, CRM-Forum, (September 1, 2002), http:// www.crm-forum.com

20. Gebert, H., Geib, M., Kolbe, L., \& Brenner, W. (2003). Knowledge-enabled customer relationship management: Integrating customer relationship management and knowledge management concepts. Journal of Knowledge Management, 7(5), 107-123.

21. Iyer, G. R., \& Bejou, D. (2003). Customer relationship management in electronic markets. Journal of Relationship Marketing, 2(3-4).

22. Kenyon, J., \& Vakola, M. (2001). Evolving the customer relationship management paradigm in the retail industry. International Journal of Customer Relationship Management, 3(4), 313-332.

23. Kenyon, J., \& Vakola, M. (2001). Evolving the customer relationship management paradigm in the retail industry. International Journal of Customer Relationship Management, 3(4), 313-332.

24. Lin, Y., \& Su, H.-Y. (2003). Strategic analysis of customer relationship management - A field study on hotel enterprises. Total Quality Management and Business Excellence, 14(6), 715-731.

25. Maas, J. (2000). Book review - The one to one manager: Real-world lessons in customer relationship management. Sloan Management Review, 41(2), 100.

26. Marjot, W. (2001). Accelerating convergence of CRM and e-Commerce. International Journal of Customer Relationshp Management,4(1), 27-34.

27. Rege, O. Stripping Down CRM to Pint-Size Simplicity, CRMGuru, (March 18, 2003), http:// www.crmguru.com.

28. Sweat, J. When CRM failure Isn't, CRMGuru, (May 16, 2002), http://www.crmguru.com.

29. Winer, R. S. (2001), A framework for customer relationship management. California Management Review, 43(4), 89-105. 